\title{
Lobbying, family concerns and the lack of political support for estate taxation ${ }^{1}$
}

\author{
Philippe De Donder ${ }^{2}$ and Pierre Pestieau ${ }^{3}$
}

26th January 2015

\footnotetext{
${ }^{1}$ We thank Yukihiro Nishimura, John E. Roemer and an anomymous referee for their comments and suggestions. The paper has been revised while the first author visited Université du Québec à Montréal. He thanks UQAM for its hospitality. Financial support from the Chaire "Marché des risques et creation de valeur" of the FdR/SCOR is gratefully acknowledged.

${ }^{2}$ Corresponding author. Toulouse School of Economics (GREMAQ-CNRS and IDEI). 21 allée de Brienne, 31015 Toulouse Cedex 6, France. Phone: (+33) 56112 85 42. Email: philippe.dedonder@tse-fr.eu

${ }^{3}$ CORE (Louvain-la-Neuve, Belgium), CREPP (ULG and HEC, Liège, Belgium), TSE (Toulouse, France). Address: 7, Bd Rectorat, LIEGE 4000, Belgium. Phone:32-4 366 3109. Fax: 32-4 366 9318. Email: p.pestieau@ulg.ac.be
} 


\begin{abstract}
We provide an explanation for why estate taxation is surprisingly little used, given the skewness of the estate distribution. Taxing estates implies meddling with intra-family decisions, which is frown upon by many. At the same time, given the concentration of estates a small proportion of the population stands to gain a lot by decreasing estate taxation. We provide an analytical model, together with numerical simulations, where agents bequeathing large estates make monetary contributions in order to play up the salience of the encroachment aspects of estate taxation on family decisions and to decrease its political support.
\end{abstract}

Keywords: estate taxation, family values, political economy, lobbying, Kantian equilibrium.

JEL codes: D72, H31, 


\section{Introduction}

Whereas wealth inequality has, on the whole, trended downwards in the 20th century, we have recently witnessed sharp reversals in a number of countries, the most striking example being the United States. ${ }^{1}$ Moreover, the distribution of inherited wealth is much more unequal than that of wealth in general. Given the extreme skewness of the distribution of inherited wealth, one would assume that a majority of households would be in favor of financing part of public expenditure/redistribution with a tax on inheritance. Yet, such a tax is not popular and one rather observes a continuous erosion of wealth transfer taxation in many OECD countries, and especially in the U.S. ${ }^{2}$ How to explain this apparent paradox is the question at the heart of this paper.

Focusing on the U.S., our line of explanation relies on the observations that a small number of very wealthy individuals make large contributions to think tanks and lobby groups whose objective is to repeal the federal estate tax, and that these groups often underscore the fact that estate taxation meddles with intrafamily decisions. As Tabarrok (2012) writes: «So long as men are mortal, wealth must be transferred between the generations and so long as parents care for their children, the dominant means of doing so will be through family inheritance. The transference of wealth through family benefits bequeather and heir, strengthens family ties, and increases long-term savings. When the state intervenes in this process, it increases its coffers at the expense of the smooth operation of family, society, and economy». Cunliffe et al (2012) further state that "inheritance taxes are viewed with suspicion because they threaten family solidarity and unity, at the especially sensitive time of the death of one of its members."

Graetz and Shapiro (2005) and Lincoln et al (2006) describe "the campaign

\footnotetext{
${ }^{1}$ See Davies and Shorrocks (2000) and more recently Piketty and Zucman (2013).

${ }^{2}$ Cremer and Pestieau (2012).
} 
of the super wealthy to kill the estate tax". These super wealthy have reported nearly half a billion dollars in lobbying expenditures from 1998 to 2006, and stand to save upward of 70 billion dollars in case of a repeal of the estate tax. They also finance think tanks and outside groups that produce "ad campaigns intended to sway public opinion against the estate tax" (Lincoln et al, 2006, p8). An example of such an outside group is The American Family Business Institute, a trade association of family business owners, farmers, and entrepreneurs. This and other organizations invest large amount of money to educate Congress, the media and the public about the costs of the estate tax in order to build pressure for a permanent repeal.

The gist of our paper is that wealth concentration makes it possible and attractive for a small fraction of the population, the super wealthy, to play up the encroachment on family decisions of estate taxation in order to draw down its political support. We model this situation as a contribution game, where very rich people endow organizations whose objective is to increase the salience for voters of family concerns, and thus to dampen their support for estate taxation. To do so, we use the concept of Kantian equilibrium, and the modeling proposed by Roemer $(2006,2010)$. We obtain numerically that the majority chosen estate tax rate is significantly decreased at the Kantian equilibrium contribution game, and we provide some comparative statics analysis. A striking result we obtain is that average donation per contributor increases when fewer people contribute.

\section{The model with exogenous salience of family values}

We consider an economy with a continuum of individuals $i$ who differ in their endowment $w_{i}$ which is distributed according to the positively skewed cdf $F\left(w_{i}\right)$, 
so that the average endowment, $\bar{w}$, is larger than the median one, $w^{\text {med }}$. Each individual has a child she cares for and allocates her endowment between consumption $c_{i}$ and bequest $b_{i}$. The government taxes bequests at a proportional rate $\theta$ and uses the tax proceeds to produce an amount $a$ of public good, with the following government budget constraint

$$
a=\theta \int b_{i} d F\left(w_{i}\right)
$$

The utility of a parent is given by

$$
U_{i}=u\left(c_{i}\right)+v\left(d_{i}\right)+a-\beta \varphi(\theta)
$$

where $u\left(c_{i}\right)$ is the utility obtained from one's own consumption and $v\left(d_{i}\right)$ is the utility derived from the endowment of the unique child, with both functions increasing and concave. ${ }^{3}$ The last term in (2) reflects the salience of the concerns that estate taxation encroaches on family decisions ("family concerns" from now on). This term is the product of the salience of this dimension, measured by $\beta \geq 0$, and of the concerns themselves, measured by the function $\varphi$ which is increasing and convex in $\theta$. This formulation embodies two assumptions: (i) the family concerns $\varphi$ depend on the value of the estate tax rate, but not on the amount of tax paid by the individual, and (ii) the multiplicative form assumed between salience $\beta$ and concerns $\varphi$ means that all agents have identical disutility from the fact that estate taxation encroaches on intra-family decisions.

We study the following three stage setting. In the first stage, the parameter $\beta$ is endogenously determined through the intensity of an advertising campaign of the wealthy, as described below in section 3. In the second stage, all parents

\footnotetext{
${ }^{3}$ This specification is often used in models where individuals are concerned with their own consumption and the initial endowment their children will benefit from. A classic reference for this is Glomm and Ravikumar (1992). The component $v\left(d_{i}\right)$ can be justified by some form of imperfect altruism.
} 
vote over the value of the estate taxation rate $\theta$. In the third stage, each parent chooses the amount of bequest $b_{i}$ she wants to leave to her offspring, and then enjoys the amount of public good $a$ described by the government budget constraint (1). Children do not take any decision.

We solve the game by backward induction, starting with the choice of bequest $b_{i}$ for given values of the estate taxation rate $\theta$ and of the salience of family values $\beta$.

\subsection{Individual bequest choice}

An individual with endowment $w_{i}$ expects her child to have an endowment reflecting a process of regression towards the mean, plus the net-of-tax bequest that she leaves to her child, so that

$$
d_{i}=\alpha w_{i}+(1-\alpha) \bar{w}+b_{i}(1-\theta)
$$

while $c_{i}=w_{i}-b_{i}$.

The individual bequest is obtained by maximizing (2) with respect to $b_{i}$, which yields

$$
\frac{\partial U_{i}}{\partial b_{i}}=-u^{\prime}\left(c_{i}\right)+v^{\prime}\left(d_{i}\right)(1-\theta) \leq 0,
$$

so that the individually optimal bequest level is affected by the estate tax rate $\theta$ (assumed exogenous at this stage) but does not depend on the salience of family concerns, $\beta$.

Assuming logarithmic utilities $u($.$) and v($.$) from now on, the first-order con-$ dition (FOC) for $b_{i}$ becomes

$$
(1-\theta) c_{i} \leq d_{i}
$$

Agents with a low endowment would prefer to leave a negative bequest, which is not allowed. To obtain the threshold parental endowment $\hat{w}(\theta)$ below which the 
individual optimal bequest is nil, we solve the following equation:

$$
\left.\frac{\partial U}{\partial b_{i}}\right|_{b_{i}=0}=0
$$

so that

$$
\hat{w}(\theta)=\frac{(1-\alpha) \bar{w}}{1-\alpha-\theta} .
$$

Note that $\hat{w}(\theta)$ increases with $\theta$, with $\hat{w}(0)=\bar{w}$ and thus $\hat{w}(\theta)>\bar{w}$ when $\theta>0$.

Since $\bar{w}>w^{\text {med }}$, a minority of agents leaves a bequest whether the tax on bequest is positive or nil. This is in accordance with stylized facts. Note that $\hat{w}(\theta)$ tends toward $\infty$ as $\theta$ tends towards $1-\alpha$ : nobody leaves bequest for $\theta \geq 1-\alpha$.

When $w_{i}>\hat{w}(\theta)$, the FOC for an interior solution for bequests is

$$
\left(w_{i}-b_{i}\right)(1-\theta)=\alpha w_{i}+(1-\alpha) \bar{w}+b_{i}(1-\theta)
$$

or

$$
\begin{aligned}
b_{i}^{*} & =\frac{w(1-\theta-\alpha)-\bar{w}(1-\alpha)}{2(1-\theta)} \\
& =\frac{w}{2}-\frac{\alpha w+(1-\alpha) \bar{w}}{2(1-\theta)},
\end{aligned}
$$

where a star denotes the individually optimal level of the variable. We then obtain that bequests increase with income and decrease with taxation: as taxation increases, the set of (rich) agents who leave a bequest shrinks and they all leave smaller bequests.

We now move backward to the second stage decision, namely majority voting over the tax rate $\theta$.

\subsection{Voting over the estate tax rate}

Since we have already established that a majority of voters (including the median income parent) never leaves a bequest, whatever the values of $\theta$ and $\beta$, we 
immediately obtain that the Condorcet winning value of $\theta$ (i.e., the value that is preferred by a majority of voters to any other feasible value) is the one mostpreferred by the individual with the median endowment, $w^{\text {med }}{ }^{4}$ The FOC for her most-preferred estate tax rate, denoted by $\theta^{V}$, is then given by

$$
\frac{\partial a}{\partial \theta}-\beta \varphi^{\prime}\left(\theta^{V}\right) \leq 0
$$

The decisive voter compares the marginal benefit of the estate tax (the increase in the amount of the public good $a$ ) with its marginal cost (in terms of the salience of family concerns). If family concerns of the estate tax have no salience $(\beta=0)$, the decisive voter chooses the value of $\theta$ that maximizes the tax proceeds. This value is interior since, as we have seen, no one leaves a bequest if $\theta \geq 1-\alpha$. It is straightforward that $\theta^{V}$ decreases as $\beta$ increases. If the salience parameter $\beta$ is large enough, the decisive voter may prefer no estate taxation at all, even though she does not contribute while she enjoys the public good. ${ }^{5}$

We now move to the first stage of the game where the salience of family concerns is determined.

\section{The setting of the salience of family concerns}

We now assume that the salience parameter $\beta$ can be affected by the intensity with which voters are faced with messages (such as media reports, interviews, talk shows, etc.) stressing that estate taxation encroaches on intra-family decisions. These messages are produced by think tanks and similar organizations, which are

\footnotetext{
${ }^{4}$ Alternatively, we can show that preferences are single-crossing in $\theta$ (see Gans and Smart (1996)) so that the median income agent would remain decisive even if a majority of parents were to leave a bequest. The proof of this statement is available upon request from the authors.

${ }^{5}$ For simplicity, we assume in the rest of the paper that $\theta^{V}>0$ (so that (5) holds with equality), in accordance with the numerical results obtained in the last section.
} 
funded by high income individuals. More precisely, we assume that agents with an endowment above some exogenous value, denoted by $\tilde{w}$, contribute voluntarily to finance these organizations. We denote by $e_{i}$ the contribution of an agent with endowment $w_{i}$, so that the per capita (in the overall population) amount of contribution, $\bar{e}$, is given by

$$
\bar{e}=\int_{\tilde{w}}^{\infty} e_{i} d F\left(w_{i}\right) .
$$

We do not model explicitly the process by which these contributions affect the salience of this issue, but rather assume that the salience parameter is an increasing and concave function of the per capita contribution, $\beta(\bar{e})$.

All agents with $w_{i} \geq \tilde{w}$ decide simultaneously how much to contribute, anticipating the impact of the resulting per capita contribution on the majority chosen estate tax rate. Our point in this paper is not to emphasize the free riding problem among rich agents in this contribution game. We rather concentrate on the Kantian equilibrium of this contribution game, as modeled by Roemer (2006, 2010). A Kantian equilibrium is such that no contributor would like to see all contributors (including himself) vary their (positive) ${ }^{6}$ contribution by the same (positive or negative) percentage. ${ }^{7}$ We write the utility function of a contributor $i$ with endowment $w_{i}$ as a function of her contribution $e_{i}$, the vector of all other individuals' contributions, $e_{-i}$, and of the common multiplicative factor $r$ as

$$
\begin{aligned}
U_{i}\left(r e_{i}, r e_{-i}\right)= & \log \left(w_{i}-b_{i}^{*}-r e_{i}\right)+a\left(\theta^{V}\right) \\
& +\log \left(\alpha w_{i}+(1-\alpha) \bar{w}+\left(1-\theta^{V}\right) b_{i}^{*}\right)-\beta(\bar{e}) \varphi\left(\theta^{V}\right),
\end{aligned}
$$

\footnotetext{
${ }^{6}$ There is always a trivial equilibrium where no one contributes, so that a proportional variation of the individual contributions does not change anything.

${ }^{7}$ We interpret the Kantian equilibrium concept as a cooperative norm: see Roemer (2010) and the references quoted there for a justification as well as a history of this concept in the economic literature, starting with Laffont (1975).
} 
where $\theta^{V}$ is the majority chosen value of $\theta$ in the next stage, given by (5) with $\beta=\beta(r \bar{e})$ and where $\bar{e}$ is given by (6). A vector of contributions $e_{i}$ for all individuals $i$ with $w_{i} \geq \tilde{w}$ is a Kantian equilibrium if the utility function (7) is maximized for all contributors when $r=1$.

Two important comments are in order. First, the majority chosen value of $\theta$ is the one emerging from voting when the salience parameter is $\beta(r \bar{e})$ for the decisive voter. At the same time, we assume that, when considering variations in their contribution to the lobbying campaign, the contributors do not affect the salience of the family dimension of estate taxation for themselves, which explains why the last term of $(7)$ is $\beta(\bar{e}) \varphi\left(\theta^{V}\right)$ rather than $\beta(r \bar{e}) \varphi\left(\theta^{V}\right)$. In other words, rich agents contribute in order to change the salience of the family issue for the decisive voter, but variations in their own contributions do not affect the salience of the issue for themselves (which would be weird). Observe that, at a Kantian equilibrium, all agents (including the contributors) share the same valence given by $\beta(\bar{e})$. One can view this situation as a long term equilibrium, where everybody is alike in the salience of family values, and where the salience of these values is supported by the contributing behavior of a fraction of high income individuals in society. ${ }^{8}$

Second, we assume that the bequest decision of agents with $w_{i} \geq \tilde{w}$ is not affected directly by the amount of contribution they make-i.e., that $b_{i}^{*}$ is given by the FOC (4) for all agents. ${ }^{9}$ Given that the contribution of wealthy indi-

\footnotetext{
${ }^{8}$ Alternatively, we could model the salience of the family issue for the contributors as $\beta(0)-$ i.e., as if contributors were immune to their own propaganda. We would then obtain that contributors would put less salience on the family dimension, at equilibrium, than the rest of the population. This would not change the function $\theta^{V}(r \bar{e})$ as long as $\tilde{w}>w^{m e d}$, since the median endowed agent would remain the decisive voter, with the same preferences as above.

${ }^{9}$ In the absence of this assumption, increasing all contributions $e_{i}$ proportionately would decrease the bequests of all contributors (because this would increase the marginal utility cost of the bequest) and would affect the shape of the government budget constraint (1). This would
} 
viduals is small compared to their wealth/bequest (see Lincoln et al, 2006), and that their marginal utility of consumption is already low and unlikely to be very much impacted by the relatively small contribution, this simplifying assumption seems quite innocuous. We verify the benign character of this assumption in our numerical simulations (see footnote 17).

We then have

$$
\left.\frac{\partial U_{i}\left(r e_{i}, r e_{-i}\right)}{\partial r}\right|_{r=1}=-\frac{e_{i}}{c_{i}}+\bar{e} \frac{\partial \theta^{V}}{\partial \bar{e}}\left[a^{\prime}\left(\theta^{V}\right)-\beta(\bar{e}) \varphi^{\prime}-\frac{b_{i}^{*}}{d_{i}}\right]=0,
$$

where

$$
\frac{\partial \theta^{V}}{\partial \bar{e}}=\frac{\beta^{\prime}(r \bar{e}) \varphi^{\prime}}{a^{\prime \prime}(\theta)-\beta \varphi^{\prime \prime}}<0,
$$

by the FOC and SOC for $\theta^{V}$. The first term in (8) is the marginal utility cost of the contribution for agent $i$. The purpose of this contribution is to decrease the tax rate $\theta^{V}$. Using the FOC for $\theta^{V}$, we can reformulate (8) as

$$
\left.\frac{\partial U_{i}\left(r e_{i}, r e_{-i}\right)}{\partial r}\right|_{r=1}=-\frac{e_{i}}{c_{i}}-\frac{b_{i}^{*}}{d_{i}} \bar{e} \frac{\partial \theta^{V}}{\partial \bar{e}}=0 .
$$

The first two terms in the square bracket of (8) cancel out because the majority chosen value of $\theta$ equalizes the marginal disutility due to family considerations with the marginal increase in public good amount. As the first term of (9) is nil when no one contributes, we obtain by continuity that (9) is positive for small values of $e_{i}$ provided that $b_{i}^{*}>0$ and that $\varphi^{\prime}>0$ when $\theta=\theta^{V}(0)$ : there is an incentive to contribute a positive amount, since the marginal cost of contributions tends to zero for very small contributions, while the benefit does not if the family concern function is sufficiently convex, and if the individual leaves a bequest at the tax rate that is majority chosen in the absence of contributions. ${ }^{10}$

We obtain the following proposition.

make both the analytical and numerical solving of the Kantian equilibrium much more complex, without any comparable gain in intuition.

${ }^{10}$ This implies that $\tilde{w}$ must be large enough so that this last condition is satisfied. 
Proposition 1 At the Kantian equilibrium, individual lobbying contributions are an affine and increasing function of income.

Proof. Integrating $e_{i}$ over $w_{i} \in[\tilde{w}, \infty[$ in (9), while making use of the FOC for $b_{i}^{*}$ (so that $\left.(1-\theta) c_{i}=d_{i}\right)$, we obtain that the Kantian equilibrium is such that

$$
1-\theta^{V}=-\frac{\partial \theta^{V}}{\partial \bar{e}} \int_{\tilde{w}}^{\infty} b_{i} d F\left(w_{i}\right),
$$

while the FOC for $e_{i}$ then simplifies to

$$
e_{i}=\frac{-\bar{e}}{1-\theta^{V}} \frac{\partial \theta^{V}}{\partial \bar{e}} b_{i}>0,
$$

so that the contribution is the same fraction of the bequest for all contributors. Since bequests are an affine function of income (see FOC (4)), the individual contribution is an affine and increasing function of income as well.

Before providing a numerical illustration, we show how our results are impacted by the introduction of an income tax.

\section{Extension: Introducing income taxation}

In this section, we add a proportional income tax on the endowment, at rate $\tau$, whose proceeds (together with the proceeds from the bequest tax) fund the public good. To keep the model as close as possible to the version developed until now, we keep the assumption that endowments are exogenous, but we assume that (unmodelled) distortions created by the income tax reduce the amount of income tax proceeds. We have

$$
\begin{aligned}
c_{i} & =(1-\tau) w_{i}-b_{i}, \\
a & =\theta \int b_{i} d F\left(w_{i}\right)+\gamma(\tau) \bar{w}
\end{aligned}
$$


with $\gamma^{\prime}(\tau) \leq 1$ and $\gamma^{\prime \prime}(\tau)<0$ so that $\gamma^{\prime}(\tau)$ is positive for $\tau$ low enough but may become negative when $\tau$ is large enough. ${ }^{11}$ The utility of the parent remains given by (2) with the child endowment $d_{i}$ given by (3). Unlike estate taxation, income taxation is not affected by family concerns, so that the function $\phi$ remains the same as in previous sections, with sole argument the estate tax rate $\theta$.

The timing of the model is unchanged: a subset of agents decide first about their lobbying contributions to affect the salience of the concerns that estate taxation encroaches on family decisions. Agents then vote over both the estate tax rate $\theta$ and the income tax rate $\tau$. Finally, they observe the resulting tax rates and choose how much they bequeath to their child. We solve this game by backward induction, as previously.

In the last stage, proceeding as in section 2.1 above, and with straightforward modifications of notation, we obtain that the smallest endowment leaving a positive bequest is

$$
\hat{w}(\theta, \tau)=\frac{(1-\alpha) \bar{w}}{(1-\theta)(1-\tau)-\alpha},
$$

with the bequest, when positive, given by

$$
b_{i}^{*}=\frac{w_{i}}{2}-\frac{(\alpha+\tau(1-\theta)) w_{i}+(1-\alpha) \bar{w}}{2(1-\theta)} .
$$

Observe that $\hat{w}$ increases with $\tau$ while $b_{i}^{*}$ decreases with $\tau$. Intuitively, income taxation discourages bequests (both at the extensive and intensive margins) because it increases the marginal utility of consumption, and thus the marginal utility cost of bequeathing. Estate taxation $\theta$ also decreases bequests, and a majority of agents leaves no bequest, whatever $\theta \geq 0$ and $\tau \geq 0$, as previously.

\footnotetext{
${ }^{11}$ In the absence of the distortions summarized by the function $\gamma(\tau)$, individuals would prefer using the non-distortive income tax to the distortive bequest tax. Introducing explicitly the distortions generated by the income tax, for instance through endogenous labor supply, would complicate the analysis without bringing much new insight.
} 
We then move backward to the second stage choice of $\tau$ and $\theta$ by majority voting. As we will show shortly, a majority of individuals (those who do not leave a bequest) shares the same preferences over $\tau$, and also over $\theta$. Whether agents vote simultaneously over pairs $(\theta, \tau)$ or separately (at the same time, or sequentially) over $\theta$ and over $\tau$ then does not matter, since the most-preferred pair of tax rates of all agents who do not bequeath is selected at equilibrium in all these procedures. For pedagogical reasons, we first study the majority chosen estate tax rate as a function of the (exogenous) income tax rate, denoted by $\theta^{V}(\tau)$, and the majority chosen income tax rate as a function of the (exogenous) estate tax rate, denoted by $\tau^{V}(\theta)$. This allows us to study and comment the substitutability/complementarity between the two taxes.

Since a majority of agents leaves no bequest, the formula for the FOC for $\theta$ is the same as in section 2.2 and given by (5). The value of $\theta$ satisfying (5) is then the majority chosen equilibrium $\theta^{V}(\tau)$.

The most-preferred value of $\tau$ of an agent with income $w_{i}$ is given by

$$
\begin{aligned}
\frac{\partial U_{i}}{\partial \tau} & =\frac{\partial a}{\partial \tau}-w_{i} u^{\prime}\left(c_{i}\right) \\
& =\frac{\partial a}{\partial \tau}-\frac{w_{i}}{(1-\tau) w_{i}-b_{i}^{*}-e_{i}}=0 .
\end{aligned}
$$

For the majority of agents who leaves no bequest and do hence not contribute to lobbying, this FOC simplifies to

$$
\frac{\partial U_{i}}{\partial \tau}=\frac{\partial a}{\partial \tau}-\frac{1}{(1-\tau)}=0
$$

where the marginal benefit of taxation (a larger amount of public good) equals its marginal utility cost. With our logarithmic utility function, the marginal utility cost of taxation is the same for all income levels who do not bequeath, so that they all share the same most-preferred value of the income tax rate, which then becomes the majority chosen one, $\tau^{V}(\theta) .{ }^{12}$

\footnotetext{
${ }^{12}$ Hence, with logarithmic utilities, the only reason to favor income taxation is the financing of
} 
The next lemma studies the substitutability between the two taxes, at the majority voting equilibrium for each tax separately.

Lemma 1 The two taxes (on estate and on income) can be either substitute $\left(\partial \tau^{V} / \partial \theta<0\right.$ and $\left.\partial \theta^{V} / \partial \tau<0\right)$ if $\partial^{2} a / \partial \theta \partial \tau<0$ or complement $\left(\partial \tau^{V} / \partial \theta>0\right.$ and $\left.\partial \theta^{V} / \partial \tau>0\right)$ if $\partial^{2} a / \partial \theta \partial \tau>0 .{ }^{13}$

The estate and income taxes can, at this level of generality, be either substitute or complement because they both affect bequests at the intensive and at the extensive margins (i.e., modifying the set of agents who do leave a positive bequest). The rest of the paper is then agnostic as to whether taxes are substitute or not. We will show in section 5 that they are substitute in our numerical simulations.

We then obtain the majority chosen tax pair $\left(\theta^{S}, \tau^{S}\right)$ as the result of the Shepsle procedure (see De Donder et al., 2012), where $\theta^{S}=\theta^{V}\left(\tau^{S}\right)$ and $\tau^{S}=\tau^{V}\left(\theta^{S}\right)$. This pair corresponds to the most-preferred tax rate pair of all agents who leave no bequest.

We now move to the lobbying equilibrium. The main difference with section 3 is that the lobbying contributions affect both the majority chosen income and estate tax rates, $\theta^{S}$ and $\tau^{S}$. We show in the following lemma how these tax rates are affected.

Lemma 2 Lobbying contributions decrease the majority chosen estate tax rate $\left(\partial \theta^{S} / \partial \bar{e}<0\right)$ and increase (resp., decrease) the majority chosen income tax rate the public good, and not redistribution. With functional forms other than Log and generating a redistribution motive -i.e., where the most-preferred value of $\tau$ is decreasing in income $w_{i}-$ the median income individual would be decisive when choosing $\tau$. This would not affect qualitatively our results, since this individual is also decisive when voting over $\theta$.

${ }^{13}$ The proofs of all formal statements in this section are to be found in the Appendix. 
if both taxes are substitute (resp., complement):

$$
\begin{aligned}
& \frac{\partial \tau^{S}}{\partial \bar{e}}>0 \text { if } \frac{\partial \tau^{V}}{\partial \theta}<0, \\
& \frac{\partial \tau^{S}}{\partial \bar{e}}<0 \text { if } \frac{\partial \tau^{V}}{\partial \theta}>0 .
\end{aligned}
$$

Recall from above that $\theta^{V}$ is affected directly by $\bar{e}$ (see (5) with $\beta=\beta(\bar{e})$ ) while $\tau^{V}$ is not (see (12)). Larger lobbying contributions raise the salience of family issues for the estate tax and unambiguously result in a lower estate tax. If both taxes are substitute (resp., complement), the majority chosen income tax rate then increases (resp., decreases) with lobbying contributions.

The FOC for the individual lobbying contribution at the Kantian equilibrium of agents with $w_{i}>\tilde{w}$ becomes

$$
\begin{aligned}
& \left.\frac{\partial U_{i}\left(r e_{i}, r e_{-i}\right)}{\partial r}\right|_{r=1} \\
= & -\frac{e_{i}}{c_{i}}+\bar{e} \frac{\partial \theta^{S}}{\partial \bar{e}}\left[\frac{\partial a}{\partial \theta}-\beta(\bar{e}) \varphi^{\prime}-\frac{b_{i}^{*}}{d_{i}}\right]+\bar{e} \frac{\partial \tau^{S}}{\partial \bar{e}}\left[\frac{\partial a}{\partial \tau}-\frac{w_{i}}{c_{i}}\right]=0,
\end{aligned}
$$

which we simplify by using the FOCs for $\tau^{S}$ and $\theta^{S}$ to obtain

$$
\begin{aligned}
& \left.\frac{\partial U_{i}\left(r e_{i}, r e_{-i}\right)}{\partial r}\right|_{r=1} \\
= & -\frac{e_{i}}{c_{i}}-\bar{e} \frac{\partial \theta^{S}}{\partial \bar{e}} \frac{b_{i}^{*}}{d_{i}}+\bar{e} \frac{\partial \tau^{S}}{\partial \bar{e}}\left[\frac{1}{1-\tau}-\frac{w_{i}}{c_{i}}\right]=0,
\end{aligned}
$$

where $c_{i}<(1-\tau) w_{i}$ for $w_{i}>\tilde{w}$ since agents who contribute to lobbying also leave a bequest (since $\tilde{w}>\hat{w}$ ), so that the square bracket in the last term is negative. ${ }^{14}$

The first term in (13) measures the marginal utility cost of increasing lobbying contributions, while the two other terms measure the utility consequences of the variations in tax rates induced by these increased contributions. Increased contributions decrease the estate tax rate, which benefits contributors in proportion

\footnotetext{
${ }^{14}$ As in section 3 , we assume that $e_{i}^{*}$ is small enough, compared to $w_{i}$, not to affect the individual bequest $b_{i}^{*}$, which is given by (10). See footnote 9 .
} 
to the amount they bequeath. Also, agents who bequeath favor a smaller income tax rate than the majority chosen value (see (11)) because they have a larger marginal utility of consumption than those who don't leave bequests. The weight they put on variations in $\tau^{S}$ induced by higher contributions is then increasing in the amount they bequeath. If both taxes are substitute, $\tau^{S}$ increases with $\bar{e}$ and the last term in (13) constitutes a cost of higher contributions, while it constitutes a benefit if both taxes are complement so that $\tau^{S}$ decreases with $\bar{e}$.

We now show that Proposition 1 is robust to the introduction of income taxation.

Proposition 2 At the Kantian equilibrium of the model with estate and income taxation, individual lobbying contributions are an affine and increasing function of income.

We now report some numerical simulations. They do not pretend to constitute a calibration, but rather an illustration of the magnitude of the forces at play in our model.

\section{$5 \quad$ Numerical results}

We assume that the endowment is distributed according to a lognormal distribution with mean 60 and median 50 (roughly corresponding, in thousand dollars, to the US household income distribution). We assume that $\alpha=0.5$, so that the endowment of a child is a simple average of the parent's endowment and of the average endowment in the economy. We use the following functional forms for the family concerns, $\varphi(\theta)=2 \theta^{6 / 5}$, for the salience function, $\beta(\bar{e})=0.1+20 \log (1+2 \bar{e})$, and for the distortions generated by income taxation, $\gamma(\tau)=\tau(1-4 \tau)$.

Figure 1 shows the majority chosen equilibrium tax rates $\left(\tau^{S}, \theta^{S}\right)$ as a function of the exogenous lobbying contributions. In other words, we solve the model from 
the second stage on, assuming exogenous values of $\bar{e}$. We represent the results of four computations, which we connect with a curve. The top left point corresponds to the case where $\beta$ is set arbitrarily at 0 . The majority voting equilibrium then corresponds to the summit of the Dupuit-Laffer curve. Moving to the right on the curve in Figure 1, we report the majority voting tax rates when $\bar{e}$ is set exogenously at, respectively, 0 (so that $\beta=0.1$ ), 0.02 (i.e., $20 \$$ per capita for the whole population, which results in $\beta=0.884$ ) and 0.05 (with $\beta=2$ ). We see that the curve is downward sloping, meaning that the two taxes are substitute. We also see that the impact on $\tau^{S}$ of increasing $\bar{e}$ is very small, while the impact on $\theta^{S}$ is, intuitively, much larger, with $\theta^{S}$ decreasing from $9 \%$ to $0.3 \%$ as we increase the per capita lobbying contributions from 0 to $50 \$ .^{15}$

[Insert Figure 1 around here]

We then solve the entire model and study the Kantian equilibrium for different values of $\tilde{w}$, and we report the results in Figure 2. We compute three Kantian allocations corresponding to lobbying contributors belonging to the top $20 \%$, top $10 \%$ and top $5 \%$ of the income distribution, respectively. We report on Figure 2 the per capita contribution $\bar{e}$ and the value of $\theta^{S}$ at the Kantian equilibrium $\left(\tau^{S}\right.$ is basically unaffected by the changes in $\tilde{w}$ ), and we connect the three allocations with a curve. We then obtain positive lobbying contributions for all three equilibria, which decrease the equilibrium estate tax rate $\theta^{S}$ from $9 \%$ (when $\bar{e}=0$, see Figure 1) to $1.6 \%$ when only the top $5 \%$ of the income distribution contribute, $1.1 \%$ when the top decile contributes, and $0.9 \%$ when the top $20 \%$ contribute. Per capita contributions (in the whole population) vary from $29 \$$ when the top

\footnotetext{
${ }^{15}$ All results reported in this section are qualitatively similar when $\tau$ is set exogenously at zero, except that equilibrium estate tax rates are slightly larger, which makes sense given that the estate tax is then the only way to fund the public good.
} 
$5 \%$ of the income distribution contribute to $37 \$$ when the top $20 \%$ do contribute. We then obtain that enlarging exogenously the set of contributors (from the top $5 \%$ to the top $20 \%$ of the income distribution) increases their total lobbying contributions and thus means that they are collectively more effective at influencing the estate tax rate. At the same time, the average contribution per contributor (as opposed to per capita in the whole population) decreases when we enlarge the set of contributors, from $590 \$$ when the top $5 \%$ contribute, to $350 \$$ when the top $10 \%$ contribute, and to $190 \$$ when the top $20 \%$ contribute.

\section{[Insert Figure 2 around here]}

We finally move to the depiction of individual lobbying contributions, as a function of income, in the three Kantian allocations studied - see Figure 3. We see that individual contributions are indeed affine and increasing in income, as shown in Proposition 2. ${ }^{16}$ We also see that individual contributions are increasing with $\tilde{w}$ (for those with $w>\tilde{w}$ ), and that the slope $\partial e_{i}^{*} / \partial w_{i}$ is also increasing with $\tilde{w} \cdot{ }^{17}$ Contributors react to an exogenous shrinking of the set of contributors by increasing their individual contributions but, as we have seen, these increases are not large enough to compensate for the lower fraction of contributors and result in a smaller per capita contribution $\bar{e}$, and thus in a larger equilibrium estate tax rate.

\footnotetext{
${ }^{16}$ The contribution of the agent with $w=\tilde{w}=80$ such that $F(80)=0.8$ is close to zero, indicating that $20 \%$ is close to the maximum proportion of contributors at any Kantian equilibrium. If we were to expand the set of contributors to people below the 8th decile of the income distribution, these agents would not leave a bequest large enough to make it worthwhile to pay lobbying contributions.

${ }^{17}$ The individual contributions remain very low even for rich agents $(700 \$$ at most for agents with a $200000 \$$ income), so that our assumption that individual bequests are not directly affected by individual contributions is reasonable.
} 
[Insert Figure 3 around here]

\section{Conclusion}

We have presented an explanation for why estate taxation receives so little popular support even though most people would not pay this tax. Our approach is based on the observations that many people see any wealth transfer tax as an encroachment on the free working of families and that this feeling is reinforced by an intense activity from organizations financed by contributions from the very wealthy. This is not the only explanation but it might be as convincing as others, such as the POUM (prospect of upward mobility) hypothesis, according to which relatively poor people oppose high rates of redistribution because of the anticipation that they or their children may move up the income ladder (Benabou and Ok, 2001). Our modelling approach is parsimonious, and would gain from being extended to the case of a progressive estate tax (for instance with a tax applied above a certain threshold, as is often the case in practice), or to a dynamic context with perfect altruism. We leave these extensions for future research. 


\section{Appendix}

\section{Proof of Lemma 1}

Direct application of the implicit function theorem on the FOC for $\theta$ (5), using the fact that the SOC is negative, shows that

$$
\frac{\partial \theta^{V}}{\partial \tau} \stackrel{s}{=} \frac{\partial^{2} a}{\partial \theta \partial \tau}
$$

Similarly for $\tau$, we have

$$
\frac{\partial \tau^{V}}{\partial \theta} \stackrel{s}{=} \frac{\partial^{2} a}{\partial \theta \partial \tau}
$$

We have that

$$
\begin{aligned}
\frac{\partial a}{\partial \theta}= & \int_{\hat{w}(\theta, \tau)}^{\infty} b_{i}^{*} d F\left(w_{i}\right)+\theta \int_{\hat{w}(\theta, \tau)}^{\infty} \frac{\partial b_{i}^{*}}{\partial \theta} d F\left(w_{i}\right) \\
& -\theta b_{i}^{*}(\hat{w}) \frac{\partial \hat{w}}{\partial \theta} f(\hat{w}),
\end{aligned}
$$

so that

$$
\begin{aligned}
\frac{\partial^{2} a}{\partial \theta \partial \tau}= & \int_{\hat{w}(\theta, \tau)}^{\infty} \frac{\partial b_{i}^{*}}{\partial \tau} d F\left(w_{i}\right)-b_{i}^{*}(\hat{w}) \frac{\partial \hat{w}}{\partial \tau} f(\hat{w}) \\
& +\theta \int_{\hat{w}(\theta, \tau)}^{\infty} \frac{\partial^{2} b_{i}^{*}}{\partial \theta \partial \tau} d F\left(w_{i}\right) \\
& -\theta f(\hat{w})\left[\frac{\partial b_{i}^{*}}{\partial \theta} \frac{\partial \hat{w}}{\partial \tau}+\frac{\partial \frac{\partial \hat{w}}{\partial \theta} b_{i}^{*}(\hat{w})}{\partial \tau}\right] .
\end{aligned}
$$

The first line of (14) is negative, the second is nil, while the square bracket in the last line simplifies to

$$
\frac{(1-\tau) \bar{w}^{2}(1-\alpha)^{2}}{\alpha-(1-\theta)(1-\tau)}<0
$$

since $\hat{w}>0$. Hence the sign of $\partial^{2} a / \partial \theta \partial \tau$ is ambiguous. 


\section{Proof of Lemma 2}

We denote the FOC for $\theta(5)$ as $F O C_{\theta}$ and the FOC for $\tau(12)$ as $F O C_{\tau}$. The pair $\left(\theta^{S}, \tau^{S}\right)$ is then the solution of the following system of two equations: $\left(F O C_{\theta}=0\right.$, and $\left.F O C \tau=0\right)$. Using the implicit function theorem applied to this system, we obtain that

$$
\begin{aligned}
|H| & =\left|\begin{array}{ll}
\frac{\partial F O C_{\theta}}{\partial \theta} & \frac{\partial F O C_{\theta}}{\partial \tau} \\
\frac{\partial F O C_{\tau}}{\partial \theta} & \frac{\partial F O C_{\tau}}{\partial \tau}
\end{array}\right| \\
& =\frac{\partial F O C_{\theta}}{\partial \theta} \frac{\partial F O C_{\tau}}{\partial \tau}-\frac{\partial F O C_{\tau}}{\partial \theta} \frac{\partial F O C_{\theta}}{\partial \tau}>0
\end{aligned}
$$

since $\left(\theta^{S}, \tau^{S}\right)$ jointly maximizes $U_{i}$. We then have

$$
\frac{\partial \theta^{S}}{\partial \bar{e}}=-\frac{\left|H_{1}\right|}{|H|}
$$

with

$$
\begin{aligned}
\left|H_{1}\right| & =\left|\begin{array}{cc}
\frac{\partial F O C_{\theta}}{\partial \bar{e}} & \frac{\partial F O C_{\theta}}{\partial \tau} \\
\frac{\partial F O C_{\tau}}{\partial \bar{e}} & \frac{\partial F O C_{\tau}}{\partial \tau}
\end{array}\right| \\
& =\frac{\partial F O C_{\theta}}{\partial \bar{e}} \frac{\partial F O C_{\tau}}{\partial \tau}>0
\end{aligned}
$$

so that

$$
\frac{\partial \theta^{S}}{\partial \bar{e}}<0
$$

while

$$
\frac{\partial \tau^{S}}{\partial \bar{e}}=-\frac{\left|H_{2}\right|}{|H|}
$$

with

$$
\begin{aligned}
\left|H_{2}\right| & =\left|\begin{array}{cc}
\frac{\partial F O C_{\theta}}{\partial \theta} & \frac{\partial F O C_{\theta}}{\partial \bar{e}} \\
\frac{\partial F O C_{\tau}}{\partial \theta} & \frac{\partial F O C_{\tau}}{\partial \bar{e}}
\end{array}\right| \\
& =-\frac{\partial F O C_{\tau}}{\partial \theta} \frac{\partial F O C_{\theta}}{\partial \bar{e}}
\end{aligned}
$$

so that

$$
\frac{\partial \tau^{S}}{\partial \bar{e}} \stackrel{s}{=}-\frac{\partial F O C_{\tau}}{\partial \theta} \stackrel{s}{=}-\frac{\partial^{2} a}{\partial \theta \partial \tau} .
$$




\section{Proof of Proposition 2}

Integrating $e_{i}$ over $w_{i} \in\left[\tilde{w}, \infty\left[\right.\right.$ in (13), while making use of the FOC for $b_{i}^{*}$ (so that $\left.(1-\theta) c_{i}=d_{i}\right)$, we obtain that the Kantian equilibrium amount of $\bar{e}$ is such that

$$
1-\theta^{S}+\int_{\tilde{w}}^{\infty} b_{i}^{*} d F\left(w_{i}\right)\left[\frac{\partial \theta^{S}}{\bar{e}}+\frac{1-\theta^{S}}{1-\tau^{S}} \frac{\partial \tau^{S}}{\bar{e}}\right]=0,
$$

while the FOC for $e_{i}$ then simplifies to

$$
e_{i}=-\bar{e} b_{i}^{*}\left[\frac{\partial \tau^{S} / \partial \bar{e}}{1-\tau^{S}}+\frac{\partial \theta^{S} / \partial \bar{e}}{1-\theta^{S}}\right]
$$

so that the contribution is the same fraction of the bequest for all contributors. Since bequests are an affine function of income (see (10)), the individual contributions are an affine and increasing function of income as well.

\section{References}

[1] Benabou, R. and E. Ok, (2001), Social Mobility and the Demand for Redistribution: The Poum Hypothesis, Quarterly Journal of Economics, 116, $447-487$

[2] Cremer, H. and P. Pestieau (2012), The economics of wealth transfer taxation, in Inherited Wealth, Justice and Equality, edited by Guido Erreygers and John Cunliffe, Routledge

[3] Cunliffe, J. G. Erreygers and A. Reeve (2012) The debate about inherited wealth and its taxation, in Inherited Wealth, Justice and Equality, edited by Guido Erreygers and John Cunliffe, Routledge.

[4] Davies, J. B. and A. F. Shorrocks, (2000), The Distribution of Wealth, in A.B. Atkinson and F. Bourguignon (eds.) Handbook of Income Distribution, North-Holland Elsevier (2000): 605-75. 
[5] De Donder Ph., M. Le Breton and E. Peluso, "Majority Voting in Multidimensional Policy Spaces : Kramer-Shepsle Versus Stackelberg", Journal of Public Economic Theory, 2012, 14(6), 879-909.

[6] Gans J. and M. Smart, 1996, Majority voting with single-crossing preferences, Journal of Public Economics, 59, 219-237.

[7] Glomm, G. and B. Ravikumar (1992) Public versus private investment in human capital: endogenous growth and income inequality, Journal of Public Economy, 1000, 818-834.

[8] Graetz M. and I. Shapiro, 2005, Death by a Thousand Cuts: The Fight over Taxing Inherited Wealth, Princeton University Press.

[9] Laffont, J.-J., 1975, Macroeconomic constraints, economic efficiency and ethics: An introduction to Kantian economics, Economica 42, 430-437.

[10] Lincoln, T., C. Collins, and L. Farris, (2006), Spending Millions to Save Billions, The Campaign of the Super Wealthy to Kill the Estate Tax, Public Citizen and United for a Fair Economy, Washington, D.C. http://www.citizen.org/documents/EstateTaxFinal.pdf

[11] Piketty, T. and G. Zucman, (2013), Capital is Back: Wealth-Income Ratios in Rich Countries 1700-2010, unpublished, Paris School of Economics

[12] Roemer, J., 2006, Party competition under private and public financing: A comparison of institutions, Advances in Theoretical Economics, 6-1, 1-31.

[13] Roemer, J., 2010, Kantian allocations, Scandinavian Journal of Economics, $112-1,1-24$. 
[14] Tabarrok, A., 2012, Death Taxes: Theory, History, and Ethics, Essays in Political Economy, Ludwig von Mises Institute, http://mises.org/journals/scholar/deathtax.pdf 


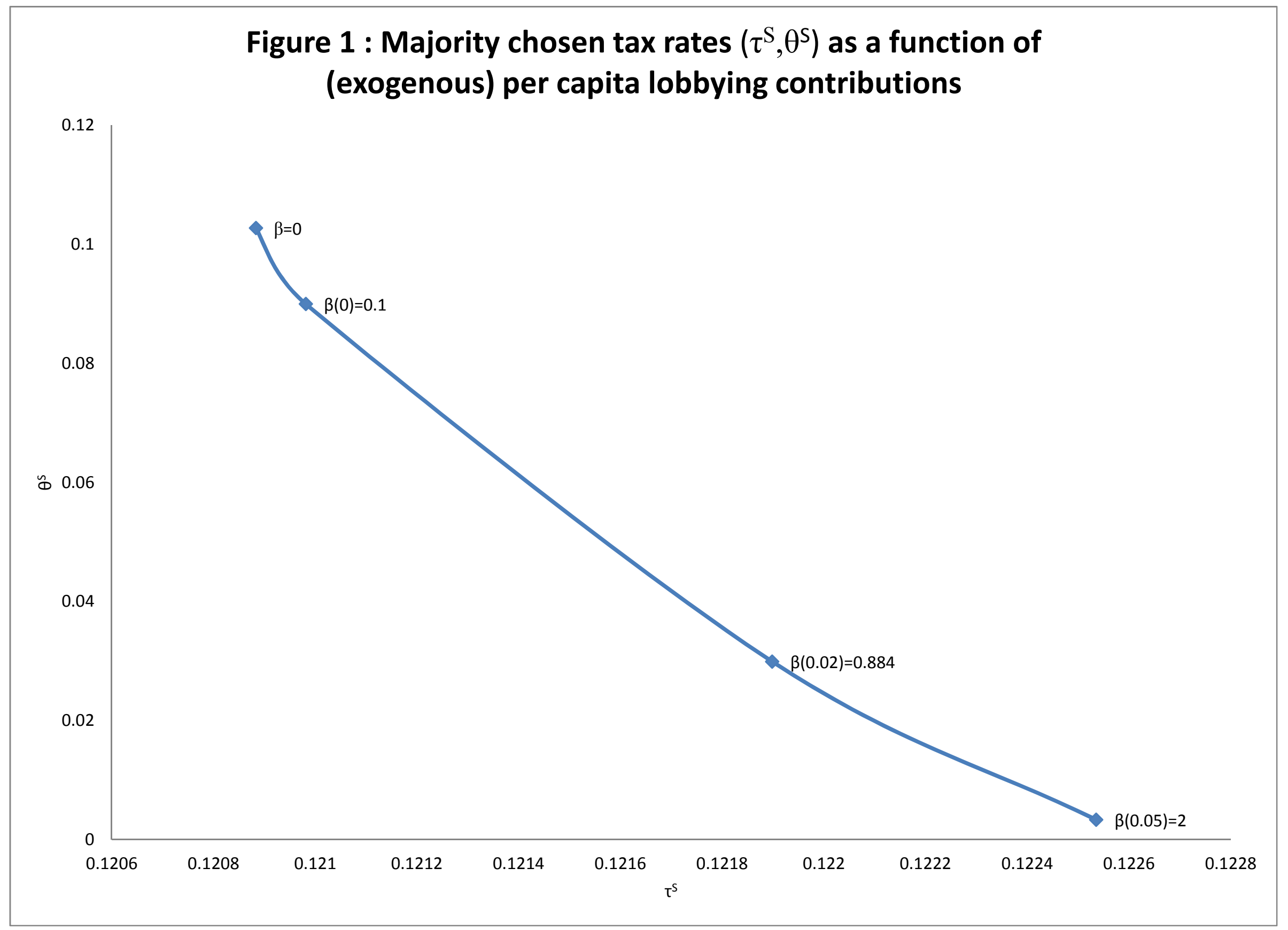




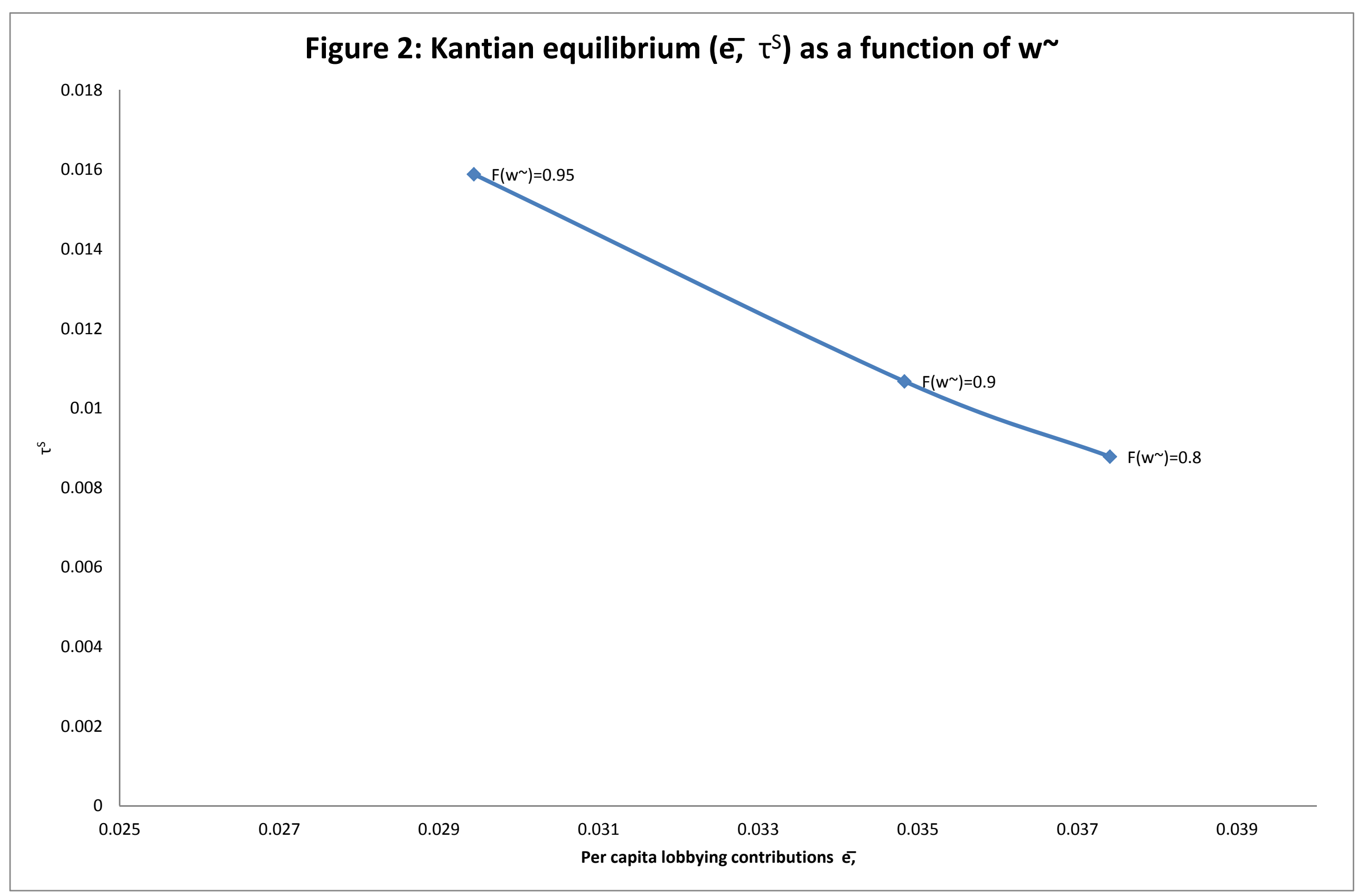


Figure 3 : Kantian individual contribution $e_{i}$ as a function of income $w_{i}$, when the set of contributors belong to the top $5 \%(\tilde{w}=135$, in dashed red), the top $10 \%$ ( $\tilde{w}=108.5$, in thick blue $)$ and the top $20 \%$ ( $\tilde{w}=83$, in green) of the income distribution

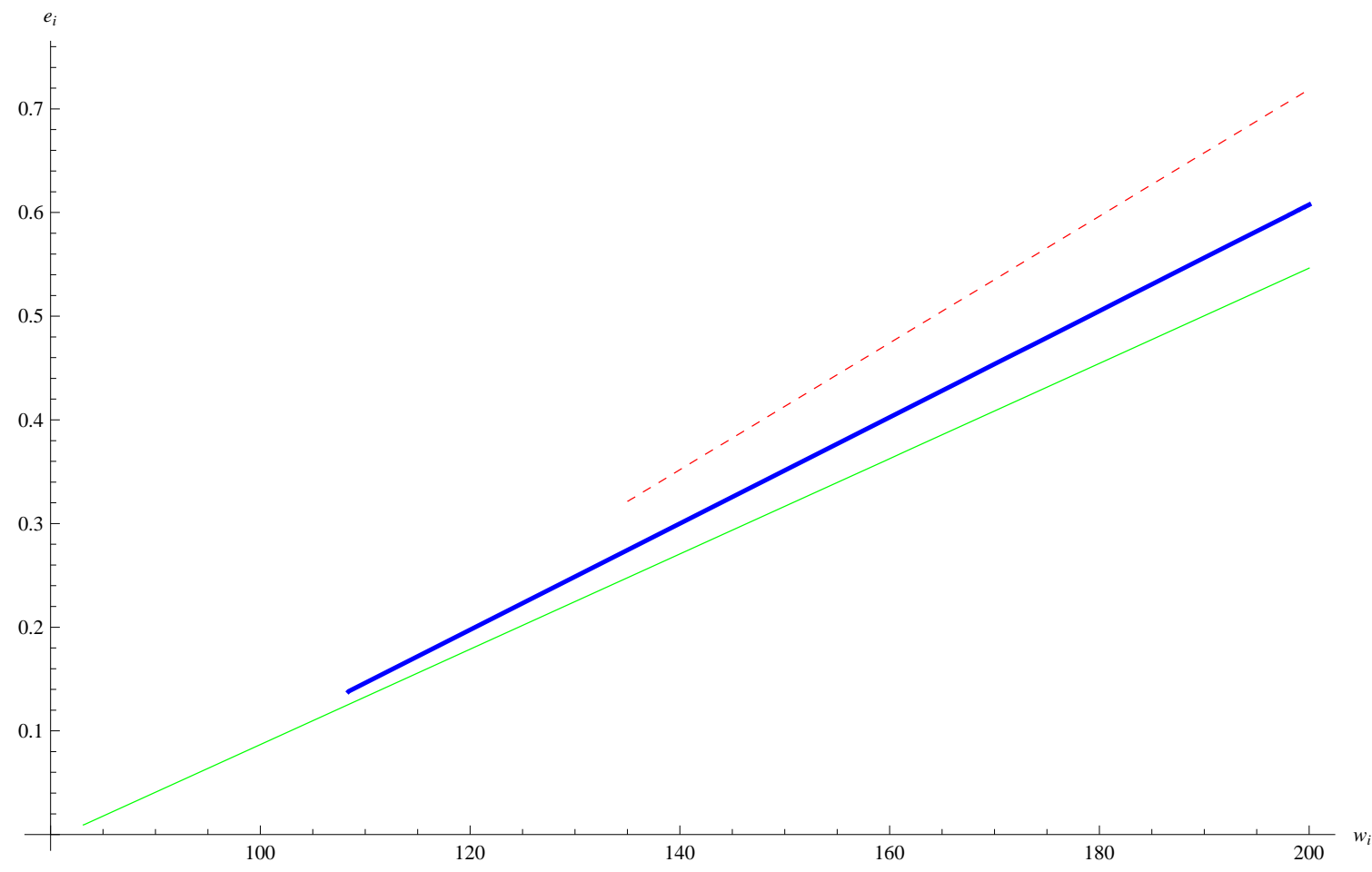

